\title{
Crisis mapping in the "senses" arena narratives
}

\author{
loanna Karantza ${ }^{1}$ (D) $\cdot$ Michael Chrissos Anestis ${ }^{2} \cdot$ Sotirios Vlachakis $^{2}$
}

Received: 14 May 2021 / Accepted: 24 October 2021 / Published online: 2 November 2021

(c) The Author(s), under exclusive licence to Springer-Verlag GmbH Germany, part of Springer Nature 2021, corrected publication 2023

\begin{abstract}
The Covid-19 pandemic is demonstrating the need for leaders to seek new solutions for supporting the pivotal role played by the non-profit context. The present paper is designed to investigate, in terms of crisis management and crisis communication, how non-profit organisations make sense through the mental map's elements: sensemaking, sense-giving, sense-breaking, and their outcomes on donors/volunteers' intentions. Firstly, a semi-structured focus group was applied with the Federation of Three Children (OPOTTE) in Greece. Then, 36 semi-structured in depth-interviews proceeded, consisting of non-profit leaders that are managing branches of the Federation across Greece. Lastly, the "questerview "technique was used to enhance the credibility of the findings. The results revealed that Greek non-profit organisations are well-organized, as they are familiar with how to cope with an emergency. However, the reality of isolation was the only unfamiliar situation that had to be addressed. The crisis presents particular opportunities for future academic research and a basis for supporting policymakers, decision-makers, and non-profit leaders, grappling with an uncertain future.
\end{abstract}

Keywords Crisis management $\cdot$ Crisis communication · Non-profit organisations (NPOs) · Covid-19

Ioanna Karantza

jkarantza@gmail.com

Michael Chrissos Anestis

michail.chrysos@gmail.com

Sotirios Vlachakis

sotirisv@mkt.teithe.gr

1 Department of Management, Birkbeck, University of London, London, UK

2 Department of Organisational Management, Marketing and Tourism, International Hellenic University, Thessaloniki, Greece 


\section{Introduction}

Almost every organisation has experienced a crisis (Spillan, 2003), but the coronavirus outbreak is "the perfect storm" (Hyndman, 2020); a high velocity cascading crisis-all in one. During this period, many non-profits had to interrupt operations or immediately adjust their service implementation structures (Kim \& Mason, 2020). In an unforeseen outbreak, "The non-profit realm" faces both management and communication crises. While NPOs have long been involved in disaster relief and recovery efforts, their incorporation into emergency management and crisis communication planning is a young field (Haupt \& Azevedo, 2021). Besides that, "no plan survives first contact with the enemy", especially a rival like Covid-19 (Denyer, 2020).

The coronavirus is not only a virus pandemic but also an infodemic (Chen $\&$ Liu, 2020). Non-profits were generally hit faster and harder, requiring more immediate and innovative responses to survive the fiscal shock (Maher et al., 2020). The level of preparedness for crises is crucial, as the "third sector" is the main communication actor in many major crises that receive substantial public attention. Changes in social behaviour are not limited to personal behaviour, affecting various aspects of life (Anastasiadou et al., 2020), making people's needs are hard to predict (Marston et al., 2020a). and establishing crisis communication planning is more critical than ever.

We've hardly noticed an era when "sense" strategies were so vital and still so difficult to achieve. The Covid-19 pandemic may be considered as a paradigm case and a rare chance to explore the "sense" arena in a novel and quickly evolving environment. When, in some way, our perception of the world becomes nonsensical, organisations with efficient "sense" capability are able to fill cognitive gaps and turn questionable circumstances into ones full of meaning (Powell \& Colyvas, 2008). Specifically, researchers have ignored how non-profit leaders develop the process of sense-making, sense-giving, and sense-breaking, during the upheaval, leaving these leaders sensitive to the full force of crises.

A significant gap in the literature is that the majority of the studies have been conducted in advanced industrial economies and little research has explored the activity of NPOs during a crisis in south-eastern Europe. While in Western Balkan countries, the NPOs were already fragile and were striving to develop, pandemic led them to lower chances of recovery. Greece pops up as an interesting case study for three reasons. First, it appears to be among the most financially affected countries in Europe (Hoikkala, 2020). Secondly, only recently Greek people have started understanding the importance of NPOs' existence as research demonstrates that they do not normally engage in voluntary action (Clarke, 2015). Thirdly, this topic is challenging, making somebody wonder which tactics have been used, by having in mind the combination of two facts: that the non-profit sector is relatively new in Greece and that according to Anastasiadou et al. (2020) people have plenty of experiences in crisis situations and are familiar with how to manage it.

Although much has been said about the side effects of the pandemic and its inflection point, scarce attention has been given to NPOs and their "sense" arena. 
Thereby, this study contributes to the illustration of the organisational activity and subsequent impacts of the NPO's "sense" strategies capability, during the pandemic crisis. Comprehending the mental map process requires a review of its prior aspects and application in the implementation of corporate tools to enhance organisational success. The remainder of the paper proceeds as follows. In the next section, a theoretical background from a review and synthesis of relevant literature are outlined presenting NPOs in crisis. Following a description of the research method with key results and findings are presented, examining the NPO as a sense-making unit, stimulated by the environmental instability, management open-mindedness, and the organizational dynamic. Finally, academic and managerial implications are discussed, drawing conclusions and offering final remarks.

\section{Literature review}

\subsection{Crisis management}

According to Coombs (2014), a crisis is identified as an incident that produces challenging and risky results. Even though many papers focus on the central planning of management during crises, post-crisis growth, and in preparation of potential crises (Deverell, 2013; DuBrin, 2013; King, 2002; Pearson \& Clair 1998) the pandemic did not provide time for non-profits to prepare using current tactics or proposals to minimize ambiguity (Shi et al., 2020). Renz (2020) has defined this as a shift from risk management to risk leadership. Additionally, short-term management addresses the maintenance of appropriate financial assets and the use of partnerships to strengthen non-profit capability (Boin et al., 2008; Christensen \& Lægreid, 2007; Egeberg, 2012; March \& Olsen, 1975; Stern, 1997). It can be hard or impossible to schedule or maintain successful relationships or to adapt to increasing service demands when current schedules, personnel, and technology are disrupted (Shi et al., 2020).

Reputation management is particularly important during a crisis which might cause unfavourable responses between stakeholders and people (Christensen and Lægreid, 2020). When an unknown crisis unexpectedly erupts, people express unpleasant feelings such as high anxiety, stress, distress, aggression, remorse, and shame (Flannery Jr, 2000). Unless these negative feelings are well managed, the successful execution of crisis management would be significantly hindered (Kanel, 2014). In the same vein, Kye and Hwang (2020) revealed that the Covid-19 pandemic crisis had a mixed influence on social trust, highlighting the value of risk management in building social trust.

The main difficulty that NPOs are facing is the lack of infrastructure and access to systems that permit working online (Nonprofit Business Advisor, 2020) due to less capital (Mano, 2010: Schwarz \& Pforr, 2011: Sisco, 2012). Even though these kinds of organisations are not profit-driven, this does not imply that they are not impacted by the financial situation, as they are dependent on donations or revenues (Sisco et al., 2010; Sisco, 2012). Sisco (2012) highlighted that NPOs ought to assess when and how to allocate their funds, and in many organisations, crisis management is regarded as a privilege that cannot be afforded. NPOs usually learn from the errors 
of other organisations, as a way for saving resources (Coombs \& Holladay, 2002). While NPOs tend to endure crises, the execution of crisis management approaches is uncertain (Bridgeland et al., 2009: Schwarz \& Pforr, 2010: Spillan, 2003). Based on surveys, approximately $30 \%$ of NPOs have a crisis management strategy in position during a crisis either due to resource problems (Bridgeland et al., 2009; Schwarz \& Pforr, 2010), or lack of knowledge of conditions within the NPO (Spillan \& Crandall, 2002; Spillan, 2003).

\subsection{Crisis communication}

Several studies analysed the effect of communication before, during, and after the crisis, with a focus on planning, data collection, organization, and transmission (Chandler, 2010; Kapucu \& Özerdem, 2011; Kapucu et al., 2013; Lindell \& Perry, 2007; McEntire, 2018; Sylves, 2014; Waugh \& Streib, 2006). Is defined as a set of activities to identify people's concerns, allocate resources, promote safety, and enhance the understanding of risk among the citizens so that organizational stakeholders and the broader community can respond jointly and wisely in crises (Bell 2010; Coombs 2007a, b; Fishman, 1999; Frandsen \& Johansen, 2011; Horsley \& Barker, 2002; Palttala \& Vos, 2011; Seeger et al., 2005; Seeger, 2006; Sellnow \& Seeger, 2001). It is proven that properly organized crisis communication could perform a significantly key role in the pandemics over time by mitigating uncertainty and fear, encouraging public commitment to response plans, and minimizing burdens (Glik, 2007).

Crisis communication studies indicate that reputation is one of the most significant assets (Doorley, 2006). The concept of a "reputation arena" states that organisations engage with their stakeholders in various forms of discursive contexts (Dowling, 2006; Romenti, 2010). The arena is the field where the company meets its components to interact. Instead of a specific place or a particular digital forum, the arena is a generic metaphor (Rowland, 1991). There are two fundamental acts of meaning in the arena of reputation: sense-giving (Gioia \& Chittipeddi, 1991) and sense-breaking (Pratt, 2000). The importance of meaning-making in the midst of the crisis relies on creating a shared and sensible message of working together to build a credible view of what is happening, of preparing how to deal with it and inform the general public (Boin et al., 2020).

While there are still cultural and structural factors that determine how communication is structured and carried out (Cheng \& Lee, 2019) the leaders' statements should reply to the emotional needs of people (Luoma-aho et al., 2013). As reported by Haupt and Azevedo (2021), there has been a substantial uptick in contributions from NPOs to respond to community needs and collaborate with local and national agencies to provide support to those facing health and economic difficulties. Crises could result in a loss of donations, and an inability to address the demands of their communities, forcing their members either to stop receiving such services or to pursue alternative non-profit services (Coombs \& Holladay, 2002, 2014). Hence, it is apparent that NPOs need to invest in crisis communication preparation to minimize 
the effects of the crises they will face (Coombs, 2014; Jordan et al., 2016; Sisco, 2012).

Carlsen et al. (2020b) emphasises the significance of social platforms in providing emotional support and has been settled as a key driver of what people comprehend and respond to (Malecki, et al., 2021; Marston et al., 2020b), particularly in circumstances of crisis such as the Covid-19 pandemic. This reinforces the fact that social media is a valuable technology for coordination in times of disaster and crisis (Albris 2018; Birkbak, 2012; Carlsen et al., 2020a). Due to the extended length of the pandemic and the challenges around it, leaders could mitigate the threat by constant interaction (Rao et al., 2020). For example, Vihalemm et al. (2012) showed that social media can help people obtain, comprehend and respond emotionally to alarm messages. Interestingly, data indicates that WOM is more powerful than many other marketing strategies (Berman, 2016). Also, Jardine et al. (2015) revealed that people usually are dependent upon information that they gain from their friends and family. This orientation has a favourable impact on results (Gummesson, 2002) particularly in the non-profit sector (Bansal \& Voyer, 2000).

\subsection{Mental maps in crisis}

\subsubsection{Sense-making}

Taking the "sense-making" concept, Weick (1995) described it as the pathway through which individuals apply sense to reality and try to interpret past, current, and potential situations. Crises often stimulate the process of sense-making "through which individuals turn flows of experience into understandings and words that serve as a springboard for action." (Sutcliffe, 2016, p.1). Sense-making is considered necessary when our perception of reality becomes incomprehensible. This phenomenon arises as the environment is evolving quickly, providing us with surprises that we are ill-prepared for, or challenging us with adaptive rather than practical decisions to make (Heifetz et al., 2009).

These experiences express an appropriate vision of the organization and its purpose in such a way that the organizational members create a "world of sensible objects and practices" through "accounts and explanations" (Gephart Jr, 2007, p.588). Sense-making is fundamentally collective as it is much easier to equate the views with those of others-blending, discussing, and implementing a widely desirable version (Sutcliffe \& Vogus, 2003). "Seeing with new eyes", and not with prejudice, allows one to look at a new situation with an open mind, to perceive it in all its special ways (Ancona, 2012). Sense-making based on real-time monitoring offers crisis communication experts the opportunity to evaluate what people think and establish rumour-rebuttal response plans and (Avery, 2017; Cheng \& Lee, 2019).

\subsubsection{Sense-giving}

Turning to the concept of "sense-giving", it allows us to explain the role of management in the sense-making process (Catasus et al., 2009). In essence, if sense-making 
is linked to the thought of defining justifications, then sense-giving refers to the idea of spreading those (Green, 2004). Sense-giving serves to normalize and validate those corporate truths while invalidating others (Gioia \& Thomas, 1996); it "shuts down alternate perceptions of reality, constrains the sense-making process and restricts that can engage in the sense-making process" (Voronov, 2008, p.201).

Sense-giving is the method of providing an updated context for the interpretation of observed incidents and the modification of predominant images (Gioia \& Chittipeddi, 1991). Its encouraging structure and direction are more highly rated in a crisis than sense-giving assisting those impacted by the crisis (Gilstrap et al., 2016). Sherman and Roberto (2020) demonstrated that crisis sense-giving messages fitting with the organisational culture are more plausible and successful at assisting sense-making.

Previous studies noted the role of the media both in spreading crises and in influencing their paths, thereby indicating that the press is a strong sense-giving tool that affects the public's sense of such incidents (Adut, 2005, 2008; Entman, 2012; Wiesenfeld et al., 2008). Allern \& Pollock (2012) also argue that a scandal is not a scandal until and unless it draws media curiosity.

\subsubsection{Sense-breaking}

In terms of "sense-breaking" (or sense-unmaking), it illustrates the way corporate participants have to destruct their senses to make sense (Almqvist, et al., 2011; Pratt, 2000 , p.464). Sense-breaking is a leader's conscious attempt to challenge the fundamental beliefs (Maitlis \& Christianson, 2014) and is discussed in-depth by others (Giuliani, 2016; Schildt et al., 2020). People attempt to view and operate on informational instructions to establish plausible inter-subjective interpretations of incidents (Maitlis \& Christianson, 2014).

Also, it could be regarded as an aspect of sense-giving since crises often inevitably lead to sense-breaking in order to encourage eventual sense-giving (Sherman \& Roberto, 2020). Some incidents represent "sense-breaking" episodes (Pratt, 2000) such as events that disrupt the existing knowledge, leading to the reconsideration of existing ways of thought and behaving (Maitlis \& Lawrence, 2007). Such occurrences (e.g. scandals) generate sense gaps where the dominant trends are not sufficient (Corley \& Gioia, 2004).

\subsection{Intention}

\subsubsection{Donating intention}

During the pandemic novel, studies have shown significant variables on donation intention. Scholars have proposed a variety of factors that strongly motivate people's attitudes towards donating money; these behavioural views are formed by perceptions that in compliance with understanding the external environment (Bin-Nashwan et al., 2020a; Kasri, 2013; Johnson \& Grimm, 2010; Sura et al., 2017). Also, proper transparency, communication, and partnership between charities and prospective 
donors must be considered (Bin-Nashwan et al., 2020b; Sura et al., 2017; Zhong \& Lin, 2018). Due to a lack of control, people might feel a lack of trust in NPO campaigns, even though they understand their utility and significance (Maftei, 2020). Regardless of the fact that sympathy influenced by emotion dissonance has indicated a positive relationship to the desire for donation intention and actual monetary donation (Park et al., 2019), the sense of solidarity revealed to have a stronger explanatory effect on these variables (Yue \& Yang, 2021). Sarea \& Bin-Nashwan (2020) studied the impact of trust showing that is manifested as individuals realise that these organisations serve their mission, are truthful about the use of donations, and give priority to the rights of their beneficiaries. Additionally, those with a deeper holistic thinking style, compared to those with less, are more likely to make donations (Zhou et al., 2021).

Most of the NPOs have taken a considerable hit across the board on fundraising (Rangone \& Busolli, 2021). More specifically, despite the NPOs' efforts, it has been noticed a decrease in funding and reported difficulties in reaching donors (Kim \& Han, 2020). Based on a survey, donations from superpower countries such as the United States, Canada, the UK, and the Netherlands gradually decreased, while Poland and the Czech Republic had the largest declines (Charities Aid Foundation, 2021). It should be also noted that trust in the non-profit sector has been decreasing as have donations worldwide (Barometer, 2018; Dong \& Lu, 2020). For example, in the UK, NPOs face a huge funding gap of almost $£ 10.1$ bn (Hyndman, 2020); in Vancouver, organisations are over-relied on fundings resulting in an inability to support core operations (City of Vancouver, 2020); in India, organisations are aggressively decreasing on overhead and non-essential expenses (Centre for Social Impact and Philanthropy, 2020); in China, The financial damages brought by the Covid-19 crisis will make the non-profit sector even more vulnerable (Dong \& Lu, 2020) as according to a survey $35 \%$ non-profits are now hardly sustaining operations, $20 \%$ are suspending programs and services, and 13\% are considering bankruptcy (China Social Enterprise and Impact Investment Forum, 2020).

\subsubsection{Volunteering intention}

Volunteers are usually seen as the backbone of NPOs (Alfes et al., 2017). During the Covid-19 pandemic, people volunteered to support the high-risk population or assisted non-profits in their services (Beardmore et al., 2020). Initially, Rosychuk et al. (2008) showed that a well-designed information policy had positive effects on willingness to volunteer in an influenza pandemic. Hence, the authors assume that the assessment of the online platforms' crisis-policy measures (e.g., the supply of health information) has a positive impact on Covid-19 volunteering satisfaction. Nevertheless, occasionally, even when accurate information about danger is presented, people's perception of the risk from an unidentified and ever-changing hazard, such as Covid-19, drives to a more emotional reaction or rage (Malecki et al., 2021). Trautwein et al. (2020) highlighted that Covid-19 volunteering was obviously a means of boosting self-confidence and revealing that volunteers who considered themselves to be vulnerable to Covid-19 infection, motive fulfilment was more pronounced. Volunteering, in particular among those with few 
social relationships, can promote well-being, allowing them to develop confidence and self-esteem by making them feel part of a community that enhances their social capital (Tierney \& Mahtani, 2020).

Meanwhile, according to Biddle \& Gray (2020), in Australia, there has been a significant decrease in volunteering activity to minimise Covid-19 transmission. They highlighted that those that have continued their volunteering activities have been less affected, as their life satisfaction and mental health have been maintained. Furthermore, UK volunteerism has faced a significant decrease with volunteers appearing to be reluctant or unable (Hyndman, 2020). In Germany, NPOs' support activities have increased along with the number of volunteers, arguing that approximately one-quarter of the volunteers are newcomers (Koos \& Bertogg, 2020). Carlsen et al. (2020b) reveal that in Denmark social media had a key role in volunteers' mobilisation compared to the situation before Covid-19 (Eimhjellen, 2019).

\section{Method}

Merits and challenges exist in using both in-depth interviews (IDI) and focus groups (FGs) in a single study. Morse (2009) suggested that mixing qualitative methods allows the emergence of different perspectives that may otherwise be overlooked. Data triangulation using FGs and IDI interviews in qualitative inquiry may result in a broader understanding of the phenomenon of interest, resulting in the triangulation method (Patton, 1999). Our primary purpose is to increase reliability, comprehensiveness (Greene et al., 1989), and to reach the effect of the increased researchers' confidence regarding the results that triangulation brings to the researchers (Jick, 1979). This means that an exploratory approach was considered suitable and the data collection includes Skype interviews, document analysis, and extensive secondary data collection, as the pandemic phenomenon is current and previous literature is scarce (Fig. 1).

\section{Data sources}

\subsection{Interviews}

First, a semi-structured focus group was proceeded with the Federation of Three Children (OPOTTE) in Greece to generate information on collective views and the meanings that lie behind those beliefs (Morgan \& Krueger, 1998). This allowed the researchers to understand the different kinds of management that the NPO developed compared to for-profit organisations. The interview covered the duration of one hour and was based on a semi-structured interview guide. The questions in the interview guide comprise the core question and many associated questions were related to the central question. In order to have the interview data captured more effectively, recording of the interviews was considered an appropriate choice (Creswell, 2007). 
Next, semi-structured in depth-interviews were applied, consisting of NPOs' heads and managers that are leading branches of the Federation across Greece. In total, 36 NPO branches out of 45 active organisations were collected across Greece. Authors suggest that 25-30 in-depth interviews are the minimum sample size to achieve saturation and redundancy in grounded theory studies that use in-depth interviews (Charmaz, 2006; Morse, 1994, 1995).

Due to the large number of interviews, to ensure the credibility of the results, a qualitative research questionnaire "questerview" methodology was applied (Adamson et al., 2004). More precisely, standardised questions to each respondent were asked to assess their effort regarding the organisation's existing communication and management crisis practices at the time of the interview concerning the "sense" terms such as sense-making, sense-giving and sense-breaking, which results in volunteer and donor intentions. A 7-point Likert scale was anchored by (1) = 'strongly disagree' and (7)= 'strongly agree' in order to provide a greater spectrum of selections and more independence to a respondent to pick the 'exact' one rather than to pick some 'nearby' or 'close' option (Dawes, 2008). Each interview lasted approximately $90 \mathrm{~min}$ and had some intrinsic worth of expressing the opinions openly by the participants (Creswell, 2007). Finally, the interviews were conducted in Greek to avoid language barriers and misinterpretations.

\subsection{Document analysis}

Analysing documents incorporates coding content into themes similar to how focus group and interview transcripts are analysed (Bowen, 2009). Based on O'Leary (2014) outline, three primary types of documents are used in present research: public records (mission statements, policy manuals, the firm's annual reports), personal documents (blogs, Facebook/Instagram posts, academic journals, newspapers), and physical evidence (posters). The information gathered from secondary sources primarily facilitated the confirmation of primary data obtained from the interviews.

\subsection{Secondary data}

The coronavirus pandemic is a current and ongoing situation, which results in limited access to previous research. Thus, we reviewed previous work on management and communication crisis during uncertainty, as NPOs' managers tend to make decisions in a different way under crisis, fear, and uncertainty (Boin et al., 2020; Christensen and Lægreid, 2020; Shi et al., 2020; Haupt and Azevedo, 2021; Kye \& Hwang, 2020; Malecki et al., 2021; Marston et al., 2020a; Carlsen et al., 2020a; Rao et al., 2020).

\section{Data analysis}

To analyse the data derived from the interviews, we implemented an inductive approach by using constant comparative analysis (Glaser \& Strauss, 1967). The purpose of grounded theory and in-depth interviews is to generate "categories from the data and 


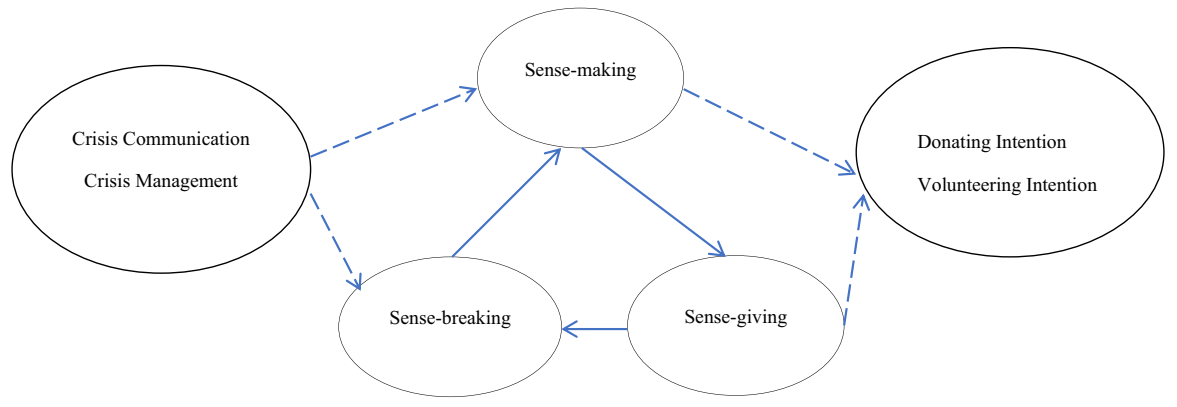

Fig. 1 Conceptual model of non-profit organizations in Crisis

then to analyse relationships between categories" while paying attention to how participants' "lived experience" can be interpreted (Charmaz, 1990, p.1162). After a repeated reading of the data, we applied open coding to develop the initial categories by "breaking down, examining, comparing, conceptualizing, and categorizing data" through the use of analytic memos (Strauss \& Corbin, 1999, p.61). Then, we used axial coding to construct linkages between the data in order to bring out categories into viable concepts (Strauss \& Corbin, 1990). The completion of the analysis arose when researchers came to a consensus (Laperrière, 1997; Paillé, 1994).

\section{Discussion on results}

After the data process, four prevailing dimensions are identified: sense-making, sensegiving, sense-breaking and intentions (donors and volunteers). The results are presented in Table 1 that illustrates the mean values for every NPO.

\subsection{Sense-making}

According to the respondents' answers, the concept of sense-making was divided into two categories. The first one concerns the "Management" including questions such as the quality of the management before and after Covid-19, the reaction during the outbreak of the pandemic, and the adaptation process into the "new normal". The second is the "Internal Communication" containing questions such as the communication before and after Covid-19 and the tools that were used.

\subsubsection{Management}

The majority of non-profit leaders made sense of organizational crises in terms of Covid-19. Specifically, the findings demonstrated that the administration of the branches is adequate. Only a few divisions manage their organisations inefficiently as they need an increase in their fundings (e.g. Agios Nikolaos). Thus, a great number of branches addressed the Covid-19 outbreak effectively at the outset, as they tried to respond to the new changes as fast as possible. The executives 


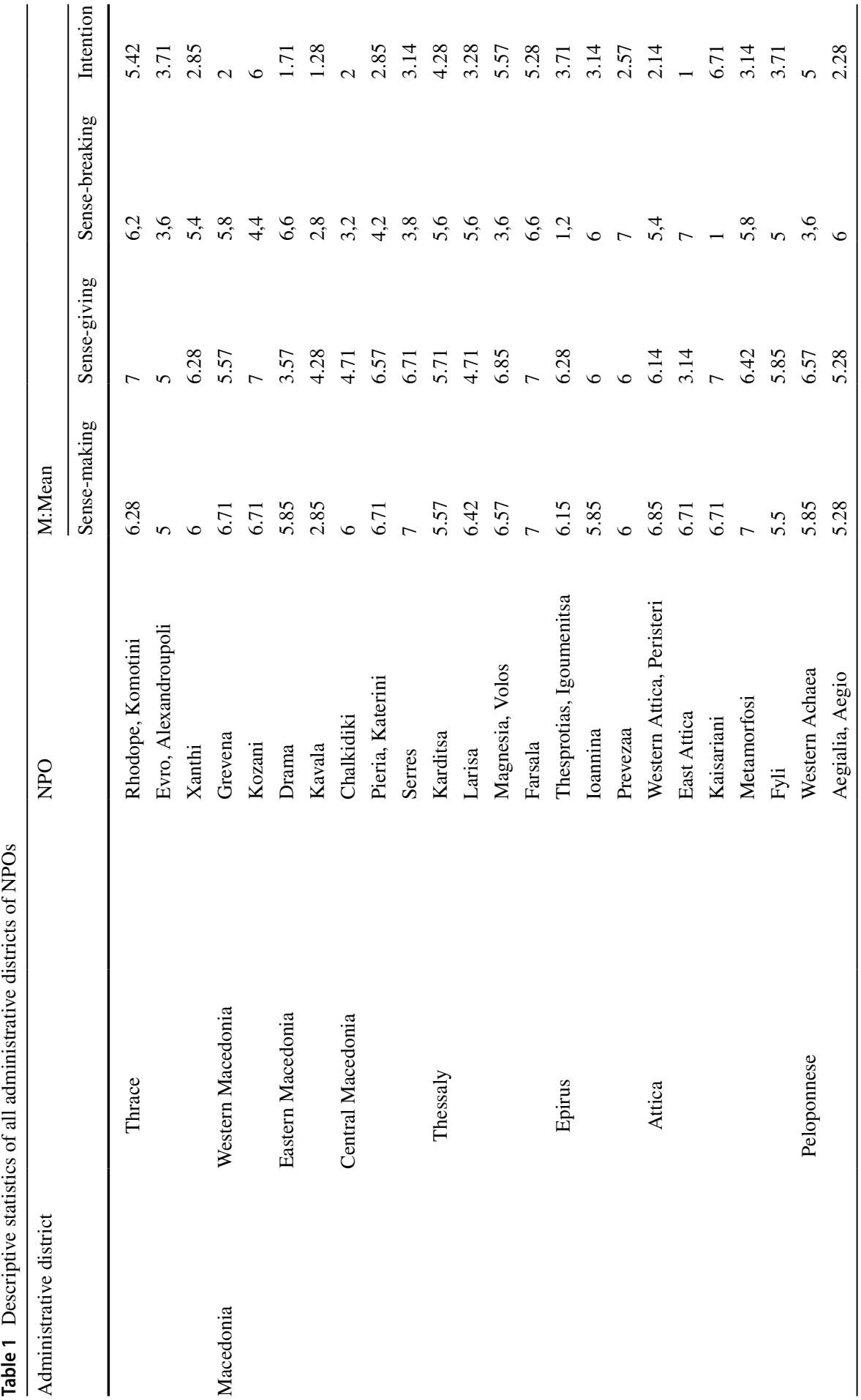




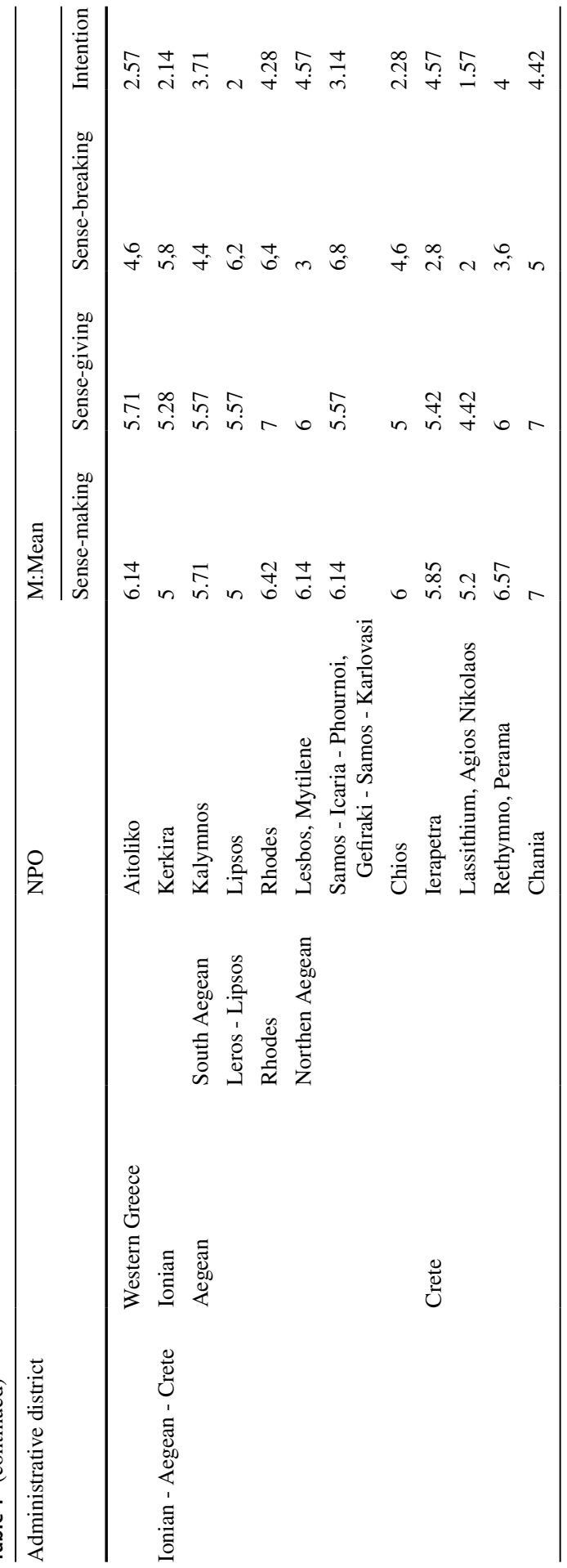


were taken aback by the sudden situation and were unaware of what actions to take and the measures that are needed.

"This kind of crisis came out of nowhere. Things were happening so quickly and we didn't know where to respond first."

Especially, after a while, once they had a deep understanding of the new situation and how people reacted to it, their efforts seemed rewarding and they attempted to respond the best they could. The departments were attempting to comprehend the situation and making decisions with an "open mind" by engaging in conversation with one another and reaching decisions after consensus. With a great deal of effort, the adaptation to the "new normal" was as effective as it should have been at the moment, as everybody responded immediately to the crisis situation. Furthermore, not all the effects of the pandemic were unfamiliar to the management. More precisely, the financial effects were something that managers had dealt with some years before due to the economic crisis. What they didn't expect was the fact of social distancing.

"We could deal with the financial effects. But what we didn't expect was the occurrence of social distancing. That was our main problem."

\subsubsection{Internal communication}

The communication between the Federation and the branches is effective, resulting in balanced and coordinated actions. More or less, the majority of the divisions are in concordance with each other, as the Federation was informing them about the issues and the necessary actions. Prior to the pandemic, not every participant member of the NPO and volunteer seemed to use social media. Thus, the decision-making process typically took place in specific venues where they could gather and negotiate face-to-face. Following the pandemic's spread, these areas were forced to shut and establish a "social media interaction" due to socialdistancing steps.

"Trying to reach everyone was one of the hardest things we had to do. The physical gathering was one of the assets for the progression of the NPO as everybody could gather and talk. After that, we tried hard to adapt to the results of social distancing and reinforce our communication through social media. Nothing is the same."

This proved to be one of the most critical concerns, as the NPO had lost touch with several members. The Federation was attempting to inform its members about its activities via the website while trying to coordinate each branch. Only after a while, almost everybody got used to the utility of social media and adapted to this kind of communication. 


\subsection{Sense-giving}

The dimension of Sense-giving was halved into "Information" and "Promotion". The former relied on questions such as the quality of communication between the NPO and its members, and the utility of social networks, before and after the coronavirus pandemic. The latter relied upon questions concerning the intensity of NPOs' image, mission and activities promotion before and after the pandemic.

\subsubsection{Information}

Overall, the communication was productive with its members before and after the pandemic of the NPO. The overwhelming majority of the NPO's branches are active on social media, and after the pandemic empowered their online presence. Nevertheless, there are some branches like in East Attica and Alexandroupoli that do not have an active presence on social media, as they were communicating mainly with face-to-face meetings and the spread of WOM. They are trying to keep their members aware of the general current situation of the pandemic, its effects on the organisation and the actions that are going to take. Also, the branches were making multiple efforts to assure and advise their members to be patient for their actions.

"We are making a huge effort to keep everybody informed about the situation. For the time being social network is a useful ally, to keep everyone updated about the current situation and NPO's actions."

The NPO undertakes efforts more than ever to highlight the members' benefits. The aim of the promotion of the members' benefits is to attract and foster more people to engage in the organisation. The members interpret those benefits as a reward for their actions. The NPO in order to fill the gaps that coronavirus brought to its function was trying to underline to its members that the effects of the pandemic were normal and that it needs patience.

\subsubsection{Promotion}

Before the pandemic, one of the most effective marketing techniques for promotion was the WOM tool. The branches used social networks only to upload some useful information and the results of their activities. After the pandemic, almost more than half of the NPO's branches, especially those in big cities, highlight their activities, their image and their purpose, as the WOM in this kind of cities is almost impossible.

"In big cities, people get lost with each other and tend to be faced with a huge amount of information. In a situation like this, we have to empower our presence on social media, as it seems the only way to get in touch with people." 
Those who are allocated in small cities do not seem to emphasize with the same volume their activities on social networks, as the WOM still has its power (e.g. East Attica, Aegio, Chalkidiki, and Drama) nor their image and purpose (e.g. East Attica, Chalkidiki, and Drama).

"In smaller cities, it's so easy to get informed, as you could learn about everything even from a little chat with your neighbour. The use of social media is almost useless."

\subsection{Sense-breaking}

The concept of sense-breaking first revealed the category of "Management" including questions about the changes that the NPO and its branches had to make, and their actions to make sense of the new situation. Next the category of "Communication" came up concerning the changes that management had to make to the communication due to the pandemic, to support the management and its members.

\subsubsection{Management}

A picture of crisis sense-breaking also emerged among non-profit leaders. By and large, the majority of the NPOs had a detrimental negative effect on their management. Most of the branches that were located in small towns, were prepared for all the disruptions caused by COVID-19 (e.g. Alexandroupoli, Igoumenitsa, Serres, Kavala, Mytilene, Volos, Kozani, Western Achaea, Kaisariani, Fyli, Agios Nikolaos, Ierapetra, and Rethymno). Thus, there have been changes in the management of the NPOs due to the pandemic either because of the negative side effects or for precaution, apart from some branches (e.g. Kaisariani, Alexandroupoli, Igoumenitsa, Chania, Agios Nikolaos, Lipsi). Additionally, problems arose with the member management process due to the pandemic excluding the NPOs in Kaisariani, Serres, Igoumenitsa, Volos, Katerini, and Rethymno.

"The pandemic's initial shock provoked a pendulum swing into the leadership management"

\subsubsection{Communication}

Except for some NPOs (e.g. Alexandroupoli, Igoumenitsa, Katerini, Kaisariani, Metamorfosi, Western Achaea, Chalkidiki, Ierapetra, and Mytilene), the pandemic has negatively affected the way NPOs communicate with the public. Gatherings are not allowed and this had a significantly negative impact on the NPO's communication process.

\footnotetext{
"As face-to-face contact is lost. We are trying through social networks to engage them but sometimes it's not enough. I believe that is a part of the Greek mentality, according to which people want to gather with each other. That is what makes them feel that they belong somewhere. Social networks are too faceless for them".
} 
Thus, several changes appeared to fill the gaps that the coronavirus left behind. Specifically, the Federation and individual NPOs empowered their presence on social media. They started uploading information about the situation on the website and Facebook and applying online meetings to decide on their next steps. Meanwhile, there were some NPOs (e.g. Igoumenitsa, Mytilini, Kaisariani, Alexandroupoli, Chalkidiki) that didn't adopt any important change.

\subsection{Intentions}

The dimension of "Intention" "was covered by the categories of "Volunteering" and "Donating". The first one shed light on the questions about the volunteers'/members' intention to participate in the NPO's activities around Greece and the effects of social networks on it. The second one answers the questions about the donors' intention and their reaction to social media.

\subsubsection{Volunteering}

In general, members do not seem willing to help during the lockdown. Hence, almost half of the NPO's branches devote more time to retain their members due to the pandemic (e.g. Katerini, Volos, Ioannina, Karditsa, Mytilene, Igoumenitsa, Kozani, Komotini, Farsala, Metamorfosi, Rhodes, Aigio, Preveza, Alexandroupoli, Lipsi, Drama, Kaisariani, Western Achaea), as their members are not willing to even pay the minor "annual membership fee". The Federation uses this tiny amount to support the community through donations.

Though, there are some exceptions where members seem to appear to have a great willingness to help on NPO's ongoing missions (e.g. Metamorfosi, Kaisariani, Alexandroupoli, Igoumenitsa, Kozani, Farsala, Rhodes, and Ierapetra). The membership increased in specific areas (e.g. Kaisariani, Volos, Alexandroupoli, Igoumenitsa, Kozani, Komotini, Farsala, and Rhodes) and notably, in a few cities the pandemic was the cause for the membership to face an increase (e.g. Kaisariani, Volos, Kozani, and Farsala).

"There is an increase in membership in small towns. People there feel more connected and vulnerable to help, as they feel that they are escaping the isolation madness."

What is more, there is a confrontation regarding the effectiveness of social media in volunteer behaviour. Half of the branches believe that there is no significant effect, while the rest of them mention that social media has an important part in the increasing number of volunteers.

\subsubsection{Donating}

Due to the already existing economic crisis of the country and the appearance of the pandemic, donations have faced a decrease all over Greece. Only two places saw an increase during the pandemic (e.g. Chania, and Western Achaea). Even though the 
donations have experienced a fall, some people seem to admit that after the recurrent crisis they are more willing to donate (e.g. Kaisariani, Kozani, Western Achaea, and Farsala).

"At the beginning of the pandemic crisis, the donations were decreasing rapidly. Almost everybody prefers to allocate their funds somewhere else. Even the members were not willing to pay the tiny annual registering fee."

Furthermore, there seems to be a debate between the NPO's branches as the one half supports that social media does not encourage donors to contribute to the organisations' vitality while the other half argues that social media have a crucial effect on donor behaviour especially in several cities (e.g. Kaisariani, Volos, Serres, Kozani, Western Achaea, Farsala, and Chania).

\section{Conclusion}

The on-going Covid-19 pandemic is an evolving humanitarian crisis that has a global impact, impinging massively upon people's lives. Non-profits face constantly changing situations, even hourly, seeking to adapt their services to the new normal. This is having an undeniable impact on Greek's non-profit- sector. Taking the sense-making process first, the NPOs accomplished to react appropriately to the outcomes of the crisis due to the efficient management before Covid-19. Non-profit leaders sought to handle the situation with an "open mind" and form a "crisis team". It was derived that in small towns the "crisis team" had greater positive effects on the NPOs' management, as they were well-organised and well-prepared to the crisis readiness. While the members of the management were not encompassed in marketing practices, communication had a non-trivial role in the vitality of the NPO. Paradoxically, each of them was familiar with how to handle an emergency, due to the economic crisis in Greece (2008). The NPOs' are imitating behaviours of previous "catastrophic events", such as the economic crisis in 2018. Even though the years passed, their management is still feeling the impact of the outcomes that this financial crisis left behind, leading the NPOs to gain the title of "problem-solvers". Hence, in the current crisis, the only unusual situation that they had to address was the one of isolation. This finding could be in accordance with Anastasiadou et al. (2020), regarding the fact that Greek people can handle a crisis due to their past.

As far as the sense-giving is concerned, the branches made an effort to form an e-communication with the members, due to isolation. Nevertheless, the spirit of their communication was based on their face-to-face meetings. Thus, the number of the members experienced a dip, as they felt more active and involved in a part of the community when they were meeting and talking directly. Only those who were familiar with social media before the crisis continued to be a part of the NPO. Notably, the majority of the members of the small towns, not only continued to support their purpose but more people joined the branch. It could be conjectured that even though social media is a vital tool for communication during Covid-19 (Albris 2018; Birkbak, 2012; Carlsen et al., 2020a; Carlsen et al., 2020b), it had a minor effect on peoples' behaviour. 
In this kind of town, it is easier to communicate with others as nearly everybody knows each other and forms connections. It is unnecessary to use social media to reach the members. Via the WOM, everyone could be made aware by the "neighbour". The kind of connection that the citizens shape, leads them to support each other and get involved in each other's activities, with the purpose feel that they do something useful during the day. Thus, the sense-giving process was easier in these places, increasing the membership. In the same vein, Pearce (1983) highlighted that volunteers feel motivated through social interactions and are influenced by the people around them. The opposite outcomes were found in the big cities as the lifestyle of people was busier and their connections with each other were not so deep.

Turning to sense-breaking, all the branches were forced to make changes in their management and communication process. They had to adapt to the government's policies regarding isolation and make efforts to sustain their members and donors. At the outset, most of them shut down and stopped their operations before realising what to do. After they comprehend the situation and the fact that the lockdown was going to "stay" for a long time in their lives, NPOs started engaging in social media and promoting their image and mission more than before.

Finally, the fact that the majority of the Greek population is on furlough, during the national Covid-19 lockdown, had a deep impact on the donors' and members' intention. With receiving almost, the minimum wage from the government, citizens crawled in the mood of "saving every drop of a penny". As a result, a significant number of NPOs' members preferred not to pay even their slight "annual membership fee". In line, the donations suffered a decrease as well. Though, it was notable that donors revealed a great intention and eagerness to donate, as soon as the "crisis recovery". It could be assumed that while the coronavirus crisis empowered peoples' sensitivity much more than any other crisis, its circumstances did not enable them to help. The Federation expects a great number of donors as soon as the coronavirus recovery. In Greece, a new "era of voluntarism and donorship" is going to arise, where the NPOs will have a significant role in the community. In congruence with previous researches, this study demonstrates that the type of crisis could have a pivotal role in human's motivation and emotions.

\section{Limitations and future research}

The findings give rise to the question of whether the changes in management and communication that we have witnessed during the Covid-19 crisis are contingent upon and limited to the crisis or if they extend beyond it. Due to the limitations in the present study, future research may develop a more robust understanding of leaders' crisis and their dynamics of the mental maps. Taking the voluntary and donating context for individuals into account could fill the gap of intentions between leaders and stakeholders in times of crisis.

Furthermore, the sample in this study focuses on just one single type of NPOs. There are other "join hands" organisations types that can be explored on how they manage and communicate in a crisis. As also Brunel and Nelson (2000) noted, the use of a single type could be a limitation itself. So, it is recommended for the 
generalization of the findings to include other types of NPOs in future studies. Notably, a further investigation could extend this body of work by covering the non-profit nature in other countries. For instance, a Cypriot perspective, with a similar social policy to the Greek one, could be enveloped.

Next, the paper was limited methodologically because of its use of the "questerviews" technique only by Adamson et al. (2004), restricted to the healthcare sector. Therefore, possible avenues for research should also enfold this issue by applying the method in the marketing field.

\section{Implications for theory and practice}

This study aims to expand our empirical understanding of whether and how NPOs can manage and communicate successfully in times of crisis. The paper presents valuable implications in both theory and practice.

Theoretically, the Covid-19 pandemic contributes to academics to pursue research on the sense dynamics: sense-making, sense-giving, and sense-breaking as a cohesive socio-cognitive process. Also, it enriches the literature body with a particular type of crisis (Covid-19) and country (Greece) as well, giving scholars a bird's-eye view of NPOs.

Practically, on the other hand, the paper highlights the critical need for non-profit administrators to navigate the Covid-19 crisis wisely to safeguard beneficiary interest by pursuing sense strategies to lever additional donors and volunteers. NPOs' leaders could refine and target their efforts by knowing which management and communication strategies would have greater influence on perceived effectiveness for volunteers versus donors. Therefore, the current research can be used as a basis for judging Covid-19 changes, as well as supporting policymakers and decisionmakers as they deal with an uncertain future. In such a context, the crisis outcomes are most prominent on the NPOs' operational phase, making it receive a significant amount of attention.

Supplementary Information The online version contains supplementary material available at https://doi. org/10.1007/s12208-021-00319-x.

Acknowledgements The authors would like to acknowledge the Federation of Three Children in Greece (OPOTTE) as well as every NPO individually for generously supporting this research.

\section{Declarations}

Conflict of interest No potential conflict of interest was reported by the authors.

\section{References}

Adamson, J., Gooberman-Hill, R., Woolhead, G., \& Donovan, J. (2004). 'Questerviews': Using questionnaires in qualitative interviews as a method of integrating qualitative and quantitative health services research. Journal of Health Services Research \& Policy, 9(3), 139-145. 
Adut, A. (2005). A theory of scandal: Victorians, homosexuality, and the fall of Oscar Wilde. American Journal of Sociology, 111(1), 213-248.

Adut, A. (2008). On scandal: Moral disturbances in society, politics, and art (Vol. 31). Cambridge University Press.

Albris, K. (2018). The switchboard mechanism: How social media connected citizens during the 2013 floods in Dresden. Journal of Contingencies and Crisis Management, 26(3), 350-357.

Alfes, K., Antunes, B., \& Shantz, A. D. (2017). The management of volunteers-what can human resources do? A review and research agenda. The International Journal of Human Resource Management, 28(1), 62-97.

Allern S, Pollock E (2012) Mediated scandals. Allern S, Pollock E, eds. Scandalous! The mediated construction of political scandals in four Nordic countries (Nordicom, Göteborg, Sweden), 9-28.

Almqvist, R., Catasús, B., \& Skoog, M. (2011). Towards the next generation of public management: A study of management control and communication in the Swedish armed forces. International Journal of Public Sector Management, 24(2), 122-145.

Anastasiadou, E., Chrissos Anestis, M., Karantza, I., \& Vlachakis, S. (2020). The coronavirus' effects on consumer behavior and supermarket activities: Insights from Greece and Sweden. International Journal of Sociology and Social Policy.

Ancona, D. (2012). Framing and acting in the unknown. S. Snook, N. Nohria, \& R. Khurana, the handbook for teaching leadership, 3-19.

Avery, E. J. (2017). Public information officers' social media monitoring during the Zika virus crisis, a global health threat surrounded by public uncertainty. Public Relations Review , 43(3), 468-476. Crossref

Bansal, H. S., \& Voyer, P. A. (2000). Word-of-mouth processes within a services purchase decision context. Journal of Service Research, 3(2), 166-177.

Barometer, E. T. (2018). Global report. Retrieved March, 28(2021), 2018-2002.

Beardmore, A., Jones, M., Biddle, M., White, J., Ismail, S., McClean, S., Gibson, A., \& Sabey, A. (2020). Apart but not alone: Neighbour support and the Covid-19 lockdown [UWE research project]. University of the West of England.

Bell, L. M. (2010). Crisis communication: The praxis of response. The Review of Communication, 10(2), $142-155$.

Berman, B. (2016). Referral marketing: Harnessing the power of your customers. Business Horizons, 59(1), 19-28.

Biddle, N., \& Gray, M. (2020). The experience of volunteers during the early stages of the COVID-19 pandemic.

Bin-Nashwan, S. A., Abdul-Jabbar, H., Aziz, S. A., \& Haladu, A. (2020a). Zakah compliance behavior among entrepreneurs: Economic factors approach. International Journal of Ethics and Systems, 36(2), 285-302.

Bin-Nashwan, S. A., Al-Daihani, M., Abdul-Jabbar, H., \& Al-Ttaffi, L. H. A. (2020b). Social solidarity amid the COVID- 19 outbreak: Fundraising campaigns and donors' attitudes. International Journal of Sociology and Social Policy. https://doi.org/10.1108/IJSSP-05-2020-0173

Birkbak, A. (2012, October). Crystallizations in the blizzard: Contrasting informal emergency collaboration in Facebook groups. In proceedings of the 7th Nordic conference on human-computer interaction: Making sense through design (pp. 428-437).

Boin, A., Ekengren, M., \& Rhinard, M. (2020). Hiding in plain sight: Conceptualizing the creeping crisis. Risk, Hazards \& Crisis in Public Policy, 11(2), 116-138.

Boin, A., McConnell, A., \& Thart, P. (2008). Governing after crisis.

Bowen, G. A. (2009). Document analysis as a qualitative research method. Qualitative research journal.

Bridgeland, J. M., McNaught, M., Reed, B., \& Dunkelman, M. (2009). The quiet crisis: The impact of the economic downturn on the nonprofit sector. Civic Enterprises.

Brunel, F. F., \& Nelson, M. R. (2000). Explaining gendered responses to "help-self" and "help-others" charity ad appeals: The mediating role of world-views. Journal of Advertising, 29(3), 15-28.

Carlsen, H. B., Ralund, S., \& Toubøl, J. (2020a, September). The solidary Relationship's consequences for the ebb and flow of activism: Collaborative evidence from life-history interviews and social media event analysis. In sociological forum (Vol. 35, no. 3, pp. 696-720).

Carlsen, H. B., Toubøl, J., \& Brincker, B. (2020b). On solidarity and volunteering during the COVID-19 crisis in Denmark: The impact of social networks and social media groups on the distribution of support. European Societies, 1-19. 
Catasus, B., Mårtensson, M., \& Skoog, M. (2009). The communication of human accounts: Examining models of sensegiving. Journal of Human Resource Costing \& Accounting.

Centre for Social Impact and Philanthropy (2020). The Impact of Covid-19 on India's nonprofit organisations: A Snapshot Report, Ashoka University https://www.sdgphilanthropy.org/system/files/202006/The\%20Impact\%20of\%20COVID-19\%20on\%20India\%E2\%80\%99s\%20Nonprofit\%20Organisa tions.pdf. Accessed 25 March 2021.

Chandler, R. C. (2010). Emergency notification. ABC-CLIO.

Charities Aid Foundation; CAF World Giving Index. Available online: https://www.cafonline.org/aboutus/ publications/2019-publications (accessed on 25 March 2021).

Charmaz, K. (1990). 'Discovering'chronic illness: Using grounded theory. Social Science \& Medicine, 30(11), 1161-1172.

Charmaz, K. (2006). Constructing grounded theory: A practical guide through qualitative analysis. Sage Publications.

Chen, J., \& Liu, W. (2020). Information Channel matters for coordination during COVID-19 pandemic: Evidence from foreigners in China. Chinese Public Administration Review, 11(2), 105-109.

Cheng, Y., \& Lee, C. J. (2019). Online crisis communication in a post-truth Chinese society: Evidence from interdisciplinary literature. Public Relations Review, 45(4), 101826.

China Social Enterprise and Impact Investment Forum. (2020). Survey report on the survival of Chinese social enterprises in early 2020. http://www.cseif.cn/Uploads/file/20200408//5e8dd601062b3. pdf. Accessed 25 March 2021.

Christensen, T., \& Lægreid, P. (2007). The whole-of-government approach to public sector reform. Public Administration Review, 67(6), 1059-1066.

Christensen, T., \& Lægreid, P. (2020). The coronavirus crisis-Crisis communication, meaning-making, and reputation management. International Public Management Journal, 23(5), 713-729.

City of Vancouver: Social Policy and Projects (2020). Social services non-profits, July 2020 https://vanco uver.ca/files/cov/social-services-npos-covid-19-impacts.pdf. Accessed 25 March 2021.

Clarke, J. (2015). Solidarity and survival: A multidisciplinary exploration of volunteering during the Greek crisis. Austerity and the third sector in Greece: Civil society at the European frontline, 67-84.

Coombs, T. W. (2007a). Crisis management and communications.

Coombs, W. T. (2007b). Protecting organization reputations during a crisis: The development and application of situational crisis communication theory. Corporate Reputation Review, 10(3), 163-176.

Coombs, W. T. (2014). Ongoing crisis communication: Planning, managing, and responding. Sage Publications.

Coombs, W. T., \& Holladay, S. J. (2002). Helping crisis managers protect reputational assets: Initial tests of the situational crisis communication theory. Management Communication Quarterly, 16(2), $165-186$.

Coombs, W. T., \& Holladay, S. J. (2014). How publics react to crisis communication efforts: Comparing crisis response reactions across sub-arenas. Journal of Communication Management.

Corley, K. G., \& Gioia, D. A. (2004). Identity ambiguity and change in the wake of a corporate spin-off. Administrative Science Quarterly, 49(2), 173-208.

Creswell, J. W. (2007). Qualitative inquiry and research design: Choosing among five approaches. SAGE Publications.

Dawes, J. (2008). Do data characteristics change according to the number of scale points used? An experiment using 5-point, 7-point and 10-point scales. International Journal of Market Research, 50(1), 61-104.

Denyer, D. (2020). Responding to the coronavirus crisis: A strategic approach to building and strengthening organizational resilience, Cranfield School of Management.

Deverell, E. (2013). Organizational learning from crisis. In Handbook of research on crisis leadership in organizations. Edward Elgar Publishing.

Dong, Q., \& Lu, J. (2020). In the shadow of the government: The Chinese nonprofit sector in the COVID19 crisis. The American Review of Public Administration, 50(6-7), 784-789.

Doorley, J. (2006). GARCIA Helio Fred. Reputation Management-The Key to Successful Public Relations and Corporate Communication.

Dowling, G. (2006). Reputation risk: It is the board's ultimate responsibility. Journal of Business Strategy.

DuBrin, A. J. (Ed.). (2013). Handbook of research on crisis leadership in organizations. Edward Elgar Publishing. 
Egeberg, M. (2012). How bureaucratic structure matters. An organizational perspective. In B. G. Peters \& J. Pierre (Eds.), The sage handbook of public administration (2nd ed., pp. 158-168). SAGE Publishing.

Eimhjellen, I. (2019). New forms of civic engagement. Implications of social media on civic engagement and organization in scandinavia. In L. S. Henriksen, K. Strømnæs, \& L. Svedberg (Eds.), Civic engagement in Scandinavia (pp. 135-152). Springer International Publishing.

Entman, R. M. (2012). Scandal and silence: Media responses to presidential misconduct. Polity.

Fishman, D. A. (1999). ValuJet flight 592: Crisis communication theory blended and extended. Communication Quarterly, 47(4), 345-375.

Flannery Jr., R. B. (2000). Post-incident crisis intervention: A risk management strategy for preventing workplace violence. Stress medicine, 16(4), 229-232.

Frandsen, F., \& Johansen, W. (2011). The study of internal crisis communication: Towards an integrative framework. Corporate Communications: An International Journal.

Gephart Jr, R. P. (2007). Crisis Sensemaking. International handbook of organizational crisis management, 123 .

Gilstrap, C. A., Gilstrap, C. M., Holderby, K. N., \& Valera, K. M. (2016). Sensegiving, leadership, and nonprofit crises: How nonprofit leaders make and give sense to organizational crisis. Voluntas: International Journal of Voluntary and Nonprofit Organizations, 27(6), 2787-2806.

Gioia, D. A., \& Chittipeddi, K. (1991). Sensemaking and sensegiving in strategic change initiation. Strategic Management Journal, 12(6), 433-448.

Gioia, D. A., \& Thomas, J. B. (1996). Identity, image, and issue interpretation: Sensemaking during strategic change in academia. Administrative Science Quarterly, 370-403.

Giuliani, M. (2016). Sensemaking, sensegiving, and sensebreaking: The case of intellectual capital measurements. Journal of Intellectual Capital, 17(2), 218-237.

Glaser, B. G., \& Strauss, A. L. (1967). The discovery of grounded theory: Strategies for qualitative research. Aldine.

Glik, D. C. (2007). Risk communication for public health emergencies. Annu. Rev. Public Health, 28, 33-54.

Green, S. E. (2004). A rhetorical theory of diffusion. Academy of Management Review, 29(4), 653-669.

Greene, J. C., Caracelli, V. J., \& Graham, W. F. (1989). Toward a conceptual framework for mixedmethod evaluation designs. Educational Evaluation and Policy Analysis, 11(3), 255-274.

Gummesson, E. (2002). Relationship marketing in the new economy. Journal of relationship marketing, 1(1), 37-57.

Haupt, B., \& Azevedo, L. (2021). Crisis communication planning and nonprofit organizations. Disaster Prevention and Management: An International Journal.

Heifetz, R., Grashow, A., \& Linsky, M. (2009). The practice of adaptive leadership: Tools and tactics for changing your organization. Harvard Business Press.

Hoikkala, H. (2020). Greece sees biggest decline in financial wellbeing in Europe. Retrieved from https:// www.bloomberg.com/news/articles/2020-06-09/Greece-sees-biggest-decline-in-financialwellbe ing-in-europe. Accessed 25 March 2021.

Horsley, J. S., \& Barker, R. T. (2002). Toward a synthesis model for crisis communication in the public sector: An initial investigation. Journal of Business and Technical Communication, 16(4), 406-440.

Hyndman, R. J. (2020). A brief history of forecasting competitions. International Journal of Forecasting, 36(1), 7-14.

Jardine, C. G., Boerner, F. U., Boyd, A. D., \& Driedger, S. M. (2015). The more the better? A comparison of the information sources used by the public during two infectious disease outbreaks. PLoS One, 10(10), e0140028.

Jick, T. D. (1979). Mixing qualitative and quantitative methods: Triangulation in action. Administrative Science Quarterly, 24(4), 602-611.

Johnson, J. W., \& Grimm, P. E. (2010). Communal and exchange relationship perceptions as separate constructs and their role in motivations to donate. Journal of Consumer Psychology, 20(3), 282-294.

Jordan, T. A., Upright, P., \& Tice-Owens, K. (2016). Crisis management in nonprofit organizations: A case study of crisis communication and planning. The Journal of Nonprofit Education and Leadership, 6(2).

Kanel, K. (2014). A guide to crisis intervention. Nelson Education.

Kapucu, N., \& Özerdem, A. (2011). Managing emergencies and crises. Jones \& Bartlett Publishers. 
Kapucu, N., Hawkins, C. V., \& Rivera, F. I. (2013). Disaster preparedness and resilience for rural communities. Risk, Hazards \& Crisis in Public Policy, 4(4), 215-233.

Kasri, R. A. (2013). Giving behaviors in Indonesia: Motives and marketing implications for Islamic charities. Journal of Islamic Marketing.

Kim, H. H., \& Han, E. (2020). The application of the theory of planned behavior to identify determinants of donation intention: Towards the comparative examination of positive and negative reputations of nonprofit organizations CEO. Sustainability, 12(21), 9134.

Kim, M., \& Mason, D. P. (2020). Are you ready: Financial management, operating reserves, and the immediate impact of COVID-19 on nonprofits. Nonprofit and Voluntary Sector Quarterly, 49(6), 1191-1209.

King, G. (2002). Crisis management \& team effectiveness: A closer examination. Journal of Business Ethics, 41(3), 235-249.

Koos, S. and Bertogg, A. (2020) Lokale Solidarität während der Corona-Krise: Wer gibt und wer erhält informelle Hilfe in Deutschland? Research Paper.

Kye, B., \& Hwang, S. J. (2020). Social trust in the midst of pandemic crisis: Implications from COVID19 of South Korea. Research in social stratification and mobility, 68, 100523.

Laperrière, A. (1997). Les critères de scientificité des méthodes qualitatives. La recherche qualitative: enjeux épistémologiques et méthodologiques, 4, 365-387.

Lerbinger, O. (2012). The crisis manager: Facing disasters, conflicts, and failures. Routledge.

Lindell, M.K. and Perry, R.W. (2007), "Planning and preparedness", in Waugh, W.L. Jr and Tierney, K. (Eds), emergency management: Principles and practice for local governments, pp. 113-139.

Luoma-aho, V., Tirkkonen, P., \& Vos, M. (2013). Monitoring the issue arenas of the swine-flu discussion. Journal of Communication Management.

Maftei, A. (2020). The more you have, the less you give? Prospective donation behavior for COVID-19 causes. Romanian Journal of Psychology, 22(1).

Maher, C. S., Hoang, T., \& Hindery, A. (2020). Fiscal responses to COVID-19: Evidence from local governments and nonprofits. Public Administration Review, 80(4), 644-650.

Maitlis, S., \& Christianson, M. (2014). Sensemaking in organizations: Taking stock and moving forward. Academy of Management Annals, 8(1), 57-125.

Maitlis, S., \& Lawrence, T. B. (2007). Triggers and enablers of sensegiving in organizations. Academy of Management Journal, 50(1), 57-84.

Malecki, K. M., Keating, J. A., \& Safdar, N. (2021). Crisis communication and public perception of COVID-19 risk in the era of social media. Clinical Infectious Diseases, 72(4), 697-702.

Mano, R. S. (2010). Organizational crisis, adaptation, and innovation in Israel's nonprofit organizations: A learning approach. Administration in Social Work, 34(4), 344-350.

March, J. G., \& Olsen, J. P. (1975). The uncertainty of the past: Organizational learning under ambiguity. European Journal of Political Research, 3(2), 147-171.

Marston, C., Renedo, A., \& Miles, S. (2020a). Community participation is crucial in a pandemic. The Lancet, 395, 1676-1678.

Marston, H. R., Musselwhite, C., \& Hadley, R. A. (2020b). COVID-19 vs social isolation: The impact technology can have on communities, social connections and citizens. The British Society of Gerontology.

McEntire, D.A. (2018), Disaster response and recovery: Strategies and tactics for resilience, Wiley, New Jersey.

Morgan, D. L., \& Krueger, R. A. (1998). The focus group guidebook. Sage.

Morse, J. M. (1995). The significance of saturation.

Morse, J. M. (2009). Mixing qualitative methods.

Morse, J. M. (Ed.). (1994). Critical issues in qualitative research methods. sage.

Nonprofit Business Advisor. (2020). Report shows global impact of pandemic on charitable sector. Nonprofit Business Advisor, 369, 7-7. https://doi.org/10.1002/nba.30779

O'Leary, Z. (2014). The essential guide to doing your research project (2nd ed.). SAGE Publications, Inc..

Paillé, P. (1994). L'analyse par théorisation ancrée. Cahier De Recherche Sociologique, 23, 147-181.

Palttala, P., \& Vos, M. (2011). Testing a methodology to improve organizational learning about crisis communication by public organizations. Journal of Communication Management.

Park, Y. N., Hyun, H., \& Jhang, J. (2019). Do emotional laborers help the needy more or less? The mediating role of sympathy in the effect of emotional dissonance on prosocial behavior. Frontiers in Psychology, 10, 118. 
Patton, M. Q. (1999). Enhancing the quality and credibility of qualitative analysis. Health Services Research, 34(5 Pt 2), 1189.

Pearce, J. L. (1983). Job attitude and motivation differences between volunteers and employees from comparable organizations. Journal of Applied Psychology, 68(4), 646.

Pearson, C. M., \& Clair, J. A. (1998). Reframing crisis management. Academy of Management Review, 23(1), 59-76.

Powell, W. W., \& Colyvas, J. A. (2008). Microfoundations of institutional theory. The Sage handbook of organizational institutionalism, 276, 298.

Pratt, M. G. (2000). The good, the bad, and the ambivalent: Managing identification among Amway distributors. Administrative Science Quarterly, 45(3), 456-493.

Rangone, A., \& Busolli, L. (2021). Managing charity 4.0 with Blockchain: A case study at the time of Covid-19. International review on public and nonprofit marketing, 1-31.

Rao, H. R., Vemprala, N., Akello, P., \& Valecha, R. (2020). Retweets of officials' alarming vs reassuring messages during the COVID-19 pandemic: Implications for crisis management. International Journal of Information Management, 55, 102187.

Renz, D. (2020). Reframing governance III. Nonprofit sector quarterly. https://nonprofitquarterly.org/refra ming-governance-3/. Accessed 25 March 2021.

Romenti, S. (2010). Reputation and stakeholder engagement: An Italian case study. Journal of Communication Management.

Rosychuk, R. J., Bailey, T., Haines, C., Lake, R., Herman, B., Yonge, O., \& Marrie, T. J. (2008). Willingness to volunteer during an influenza pandemic: Perspectives from students and staff at a large Canadian university. Influenza and Other Respiratory Viruses, 2(2), 71-79.

Rowland, R. C. (1991). On generic categorization. Communication Theory, 1(2), 128-144.

Sarea, A., \& Bin-Nashwan, S. A. (2020). Guide to giving during the COVID-19 pandemic: The moderating role of religious belief on donor attitude. International Journal of Ethics and Systems.

Schildt, H., Mantere, S., \& Cornelissen, J. (2020). Power in sensemaking processes. Organization Studies, 41(2), 241-265.

Schwarz, A., \& Pforr, F. (2010). Krisenkommunikation deutscher Verbände. In Handbuch Verbandskommunikation (pp. 353-377). VS Verlag für Sozialwissenschaften.

Schwarz, A., \& Pforr, F. (2011). The crisis communication preparedness of nonprofit organizations: The case of German interest groups. Public Relations Review, 37(1), 68-70.

Seeger, M. W. (2006). Best practices in crisis communication: An expert panel process. Journal of Applied Communication Research, 34(3), 232-244.

Seeger, M. W., Ulmer, R. R., Novak, J. M., \& Sellnow, T. (2005). Post-crisis discourse and organizational change, failure and renewal. Journal of Organizational Change Management.

Sellnow, T. L., \& Seeger, M. (2001). Exploring the boundaries of crisis communication: The case of the 1997 Red River Valley flood. Communication Studies, 52(2), 153-167.

Sherman, W. S., \& Roberto, K. J. (2020). Are you talkin'to me?: The role of culture in crisis management sensemaking. Management Decision.

Shi, Y., Jang, H. S., Keyes, L., \& Dicke, L. (2020). Nonprofit service continuity and responses in the pandemic: Disruptions, ambiguity, innovation, and challenges. Public Administration Review, 80(5), $874-879$.

Sisco, H. F. (2012). Nonprofit in crisis: An examination of the applicability of situational crisis communication theory. Journal of Public Relations Research, 24(1), 1-17.

Sisco, H. F., Collins, E. L., \& Zoch, L. M. (2010). Through the looking glass: A decade of red cross crisis response and situational crisis communication theory. Public Relations Review, 36(1), 21-27.

Spillan, J. E. (2003). An exploratory model for evaluating crisis events and Managers' concerns in nonprofit Organisations. Journal of contingencies and crisis management, 11(4), 160-169.

Spillan, J. E., \& Crandall, W. (2002). Crisis planning in the nonprofit sector: Should we plan for something bad if it may not occur? Southern Business Review, 27(2), 18.

Stern, E. (1997). Crisis and learning: A conceptual balance sheet. Journal of contingencies and crisis management, 5(2), 69-86.

Strauss, A., \& Corbin, J. (1990). Basics of qualitative research. Sage publications.

Strauss, AL, \& Corbin, J. (1999). Fundamentals of qualitative research: Procedures and techniques of the grounded theory method.

Sura, S., Ahn, J., \& Lee, O. (2017). Factors influencing intention to donate via social network site (SNS): From Asian's perspective. Telematics and Informatics, 34(1), 164-176. 
Sutcliffe, K. M., \& Vogus, T. J. (2003). Organizing for resilience. In K. S. Cameron, J. E. Dutton, \& R. E. Quinn (Eds.), Positive organizational scholarship: Foundations of a new discipline (pp. 94-110). Berrett-Koehler.

Sutcliffe, K. M. (2016). Sensemaking. In M. Augier \& D. Teece (Eds.). The Palgrave Encyclopedia of Strategic Management. https://doi.org/10.1057/978-1-349-94848-2_371-1

Sylves, R. (2014). Disaster policy and politics: Emergency management and homeland security. CQ Press.

Tierney, S., \& Mahtani, K. (2020). Volunteering during the COVID-19 pandemic: What are the potential benefits to people's well being. CEBM Research.

Trautwein, S., Liberatore, F., Lindenmeier, J., \& von Schnurbein, G. (2020). Satisfaction with informal volunteering during the COVID-19 crisis: An empirical study considering a Swiss online volunteering platform. Nonprofit and Voluntary Sector Quarterly, 0899764020964595.

Vihalemm, T., Kiisel, M., \& Harro-Loit, H. (2012). Citizens' response patterns to warning messages. Journal of contingencies and crisis management, 20(1), 13-25.

Voronov, M. (2008). Toward a practice perspective on strategic organizational learning. The Learning Organization, 15(2), 195-221.

Waugh, W. L., \& Streib, G. (2006). Collaboration and leadership for effective emergency management. Public Administration Review, 66(1), 131-140.

Weick, K. E. (1995). Sensemaking in organizations (Vol. 3). Sage.

Wiesenfeld, B. M., Wurthmann, K. A., \& Hambrick, D. C. (2008). The stigmatization and devaluation of elites associated with corporate failures: A process model. Academy of Management Review, 33(1), 231-251.

Yue, Z., \& Yang, J. Z. (2021). Compassionate goals, prosocial emotions, and prosocial behaviours during the COVID-19 pandemic. Journal of Community \& Applied Social Psychology.

Zhong, Z. J., \& Lin, S. (2018). The antecedents and consequences of charitable donation heterogeneity on social media. International Journal of Nonprofit and Voluntary Sector Marketing, 23(1), 1-11.

Zhou, X. Z., Requero, B., Gonçalves, D., \& Santos, D. (2021). Every penny counts: The effect of holisticanalytic thinking style on donation decisions in the times of Covid-19. Personality and Individual Differences, 175, 110713.

Publisher's note Springer Nature remains neutral with regard to jurisdictional claims in published maps and institutional affiliations.

Springer Nature or its licensor (e.g. a society or other partner) holds exclusive rights to this article under a publishing agreement with the author(s) or other rightsholder(s); author self-archiving of the accepted manuscript version of this article is solely governed by the terms of such publishing agreement and applicable law. 